\title{
CORROSÃo EM ESTRUTURAS METÁlicAs: UMA BREVE Discussão ACERCA dA PREVENÇÃo EM TORRES DE TELECOMUNICAÇÕES
}

\author{
AMARAL, Cristiano Torres ${ }^{1}$; CORREIA, Martineli Priscila ${ }^{2}$ \\ e PEREIRA, Paulo Tibúrcio ${ }^{3}$ \\ ${ }^{1,2,3}$ Centro Universitário de Belo Horizonte - UNIBH \\ Departamento de Ciências Exatas e Tecnologia - Engenharia de Telecomunicações \\ Avenida Professor Mário Werneck 1685 - Belo Horizonte, Estoril CEP: 30455-610 \\ E-mail: crisweb@ig.com.br ${ }^{1}$; $\underline{\text { martineli.correia@gmail.com }}{ }^{2}$ e ptiburcio@acad.unibh.br ${ }^{3}$
}

\begin{abstract}
Resumo - Este artigo apresenta uma breve discussão acerca dos processos corrosivos em estruturas metálicas utilizadas em sistemas de telecomunicações. A corrosão é um problema relevante em torres metálicas que sustentam antenas de redes de radiocomunicações e sistemas wireless. Trata-se de um fenômeno natural, que promove a deterioração de um material, geralmente metálico, por meio de uma ação química ou eletroquímica. Neste sentido, os autores discutem esse processo, bem como mecanismos existentes para a sua prevenção, especialmente a galvanização de componentes metálicos que compõem as torres de telecomunicações.
\end{abstract}

Palavras-chave - Corrosão; Gavalnização; Estruturas Metálicas.

Abstract - This paper examines that corrosive processes in structures steel used in telecommunications systems. The corrosion is the major problem in metal towers that support networks of radio antennas and wireless systems. This is a natural phenomenon, which promotes the deterioration of a material, usually metal, through a chemical or electrochemical action. Therefore, the authors discuss this process, and existing mechanisms for its prevention, especially galvanizing of metal components that make up the towers of telecommunications.

keywords - Corrosion; Galvanization; Structural Steel.

\section{INTRODUÇÃO}

As ondas eletromagnéticas, amplamente utilizadas em telecomunicações, possuem algumas limitações físicas, especialmente nas freqüências elevadas, as quais dificultam sua passagem por obstáculos físicos significativos. Trata-se de um princípio físico que determina uma característica conhecida como radiovisibilidade [1]. Neste sentido, as antenas que possuem a fonte emissora das ondas de rádio necessitam "enxergar" as antenas receptoras de seus sinais. Para que isso ocorra de forma satisfatória, essas antenas devem estar localizadas em pontos privilegiados topograficamente, ou supridas de torres elevadas para sua sustentação em "linha de visada direta" tanto para transmissão quanto para recepção. As torres mais comuns utilizadas em telecomunicações podem ser observadas na Figura 1 a seguir:
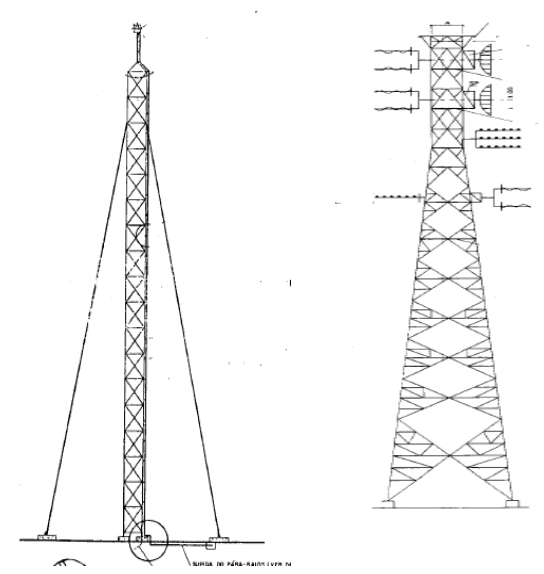

Figura 1. Tipos de Torres em Telecomunicações: Estaiada (esquerda) e Autoportante (direita) [2].

Essas torres possibilitam a elevação das antenas para a propagação dos sinais de radiofreqüência sem obstáculos visuais e, consequentemente, a perfeita comunicação em longas distâncias. As torres de telecomunicações são projetadas em função de diversos aspectos técnicos, uma vez que essas devem elevar as antenas em uma altura 
razoável, além de ficarem expostas ao meio ambiente e sujeitas à ação do tempo por um longo período. Em função disso, tais aspectos são considerados no momento da escolha do material adequado para a fabricação dessa estrutura. Dentre os materiais mais utilizados na fabricação das torres de telecomunicações destacam-se os metais, devido sua resistência mecânica, facilidade para montagem e manutenção da estrutura em campo. Porém, os metais estão sujeitos a um fenômeno comum na natureza conhecido por corrosão [3].

Denominada pelo público leigo como "ferrugem", o produto da corrosão danifica as estruturas metálicas das torres de telecomunicações, causando inúmeros prejuízos para o setor. Neste processo, as torres podem sofrer com abalos em sua estrutura física, agravados pela ação dos ventos, ou mesmo com a deflexão dos ângulos de irradiação das antenas pelo seu entortamento.

\section{CORROSÃO: CONCEITOS E FORMAS MAIS COMUNS EM TELECOMUNICAÇÕES}

Entende-se por corrosão a deterioração de um material, geralmente metálico, por ação química ou eletroquímica do meio ambiente, aliada ou não a esforços mecânicos [3]. A deterioração representa alterações prejudiciais indesejáveis, sofridas pelo material, tais como desgaste, variações químicas ou modificações estruturais, as quais podem ser relevantes em uma torre metálica que integra um sistema de telecomunicações.

A corrosão ocorre devido aos fenômenos da oxidação, que consiste na perda de elétrons por uma espécie química, e da redução, que é o ganho de elétrons por uma espécie química [3]. A corrosão é, em geral, um processo espontâneo e, para sua prevenção, é necessário o emprego de mecanismos protetores. Assim, o fato da corrosão ser, em geral, um fenômeno de superfície, faz supor que ela possa ser controlada pelas propriedades do produto de corrosão. Logo, o composto metálico formado pode agir como uma barreira entre o meio corrosivo e o metal, diminuindo assim, a velocidade de corrosão [3].

Dentre os metais mais comuns utilizados em torres de telecomunicações, o aço inoxidável sofre a corrosão com a presença do íon cloreto. Por sua vez, o alumínio, matéria prima de antenas e conectores, são corroídos com facilidade na presença de ácido clorídrico e soluções de bases fortes, como hidróxido de sódio e sais de mercúrio. $\mathrm{O}$ cobre, presente nos cabos de antenas e cordoalhas de aterramento, ou mesmo suas ligas, sofre a corrosão acentuada quando submetido às soluções amonicais [3]. Logo abaixo são apresentadas as reações químicas (1) e (2) que descrevem a oxidação e redução no ferro e alumínio, respectivamente, onde $\Delta$ representa aquecimento:

$$
\begin{gathered}
2 \mathrm{Fe}+\mathrm{O}_{2} \stackrel{\Delta}{\rightarrow} 2 \mathrm{FeO} \\
4 \mathrm{Al}+3 \mathrm{O}_{2} \stackrel{\Delta}{\rightarrow} 2 \mathrm{Al}_{2} \mathrm{O}_{3}
\end{gathered}
$$

Estas reações ocorrem simultaneamente, ou seja, existe a variação do número de oxidação e, em alguns casos, a perda e ganho de elétrons. Esse tipo de reação é denominado de reação REDOX ou OxiRedução. Nesse caso, existe um agente redutor que é a substância ou o íon que contém o elemento redutor. $\mathrm{O}$ agente oxidante representa a substância ou íon que contém o elemento oxidante. $\mathrm{O}$ elemento oxidado (perde elétrons) age como agente redutor, e o elemento reduzido (recebe elétrons) age como agente oxidante [3].

Os processos corrosivos são considerados reações químicas heterogêneas ou reações eletroquímicas que se passam geralmente na superfície de separação entre o metal e o meio corrosivo. Os tipos de corrosão mais comuns nos metais utilizados em estruturas de torres de telecomunicações são observados na descrição a seguir e Figura 2 subsequente:

a) Uniforme: a corrosão se processa em toda a extensão da superfície, ocorrendo perda uniforme da espessura. 
b) Por placas: a corrosão se localiza em regiões da superfície metálica e não em toda sua extensão, formando escavações em placas.

c) Alveolar: sulcos ou escavações na superfície do metal em forma de alvéolos.

d) Intergranular: a corrosão ocorre entre os grãos da rede cristalina do metal, ocorrendo fraturas.

e) Intragranular: a corrosão ocorre nos grãos da rede cristalina do metal, ocorrendo fraturas.

f) Filiforme: corrosão ocorre sob a forma de pequenos filamentos, geralmente em superfícies metálicas revestidas com tintas ou outros metais.

g) Puntiforme: Pequenos pontos em áreas localizadas da superfície do metal, produzindo os chamados "pites".

h) Esfoliação: ocorre em diferentes camadas do material, provocando inchaços na superfície.

i) Dezincificação: é a corrosão que ocorre em ligas de cobre-zinco (latões), e conhecida como corrosão seletiva, pois tem-se preferência pelo zinco e ferro nas ligas.

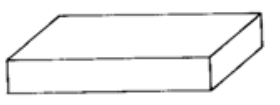

Placa Sem Corrosão

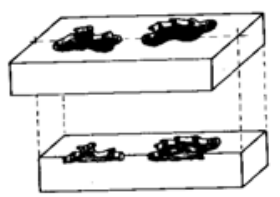

Corrosão em Placas

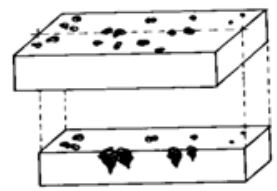

Corrosão Puntiforme (Pite)

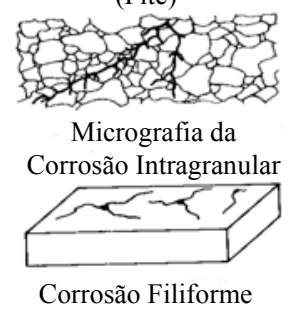

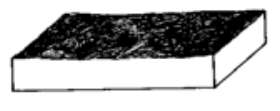

Corrosão Uniforme

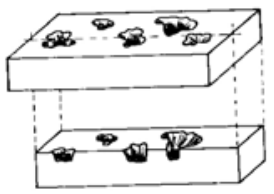

Corrosão Alveolar

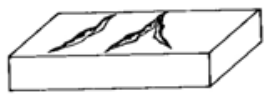

Exposição da

Corrosão

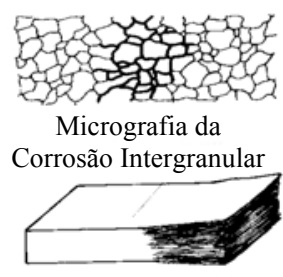

Corrosão por Esfoliação Intra/Intergranular

Figura 2. Tipos de Corrosão em Metais Utilizados em Torres [3].
A corrosão nos metais das estruturas das torres ocorre em função do meio ao qual o elemento de fabricação está submetido. Para tanto, os meios corrosivos mais relevantes são:

a) Águas naturais: a corrosão pelo contato com água dependerá da matéria orgânica dissolvida, presença de bactérias e microorganismos e sólidos em suspensão.

b) Atmosfera: a corrosão atmosférica dependerá da temperatura, umidade relativa, partículas em suspensão e gases.

c) Solo: a corrosão pelo contato com o solo deverá ocorrer em função da porosidade, condutividade elétrica, umidade, sais dissolvidos, $\mathrm{Ph}, \quad$ bactérias e microorganismos.

A Figura 3 abaixo apresenta um exemplo típico de corrosão na área de contato da torre metálica e sua base de sustentação:

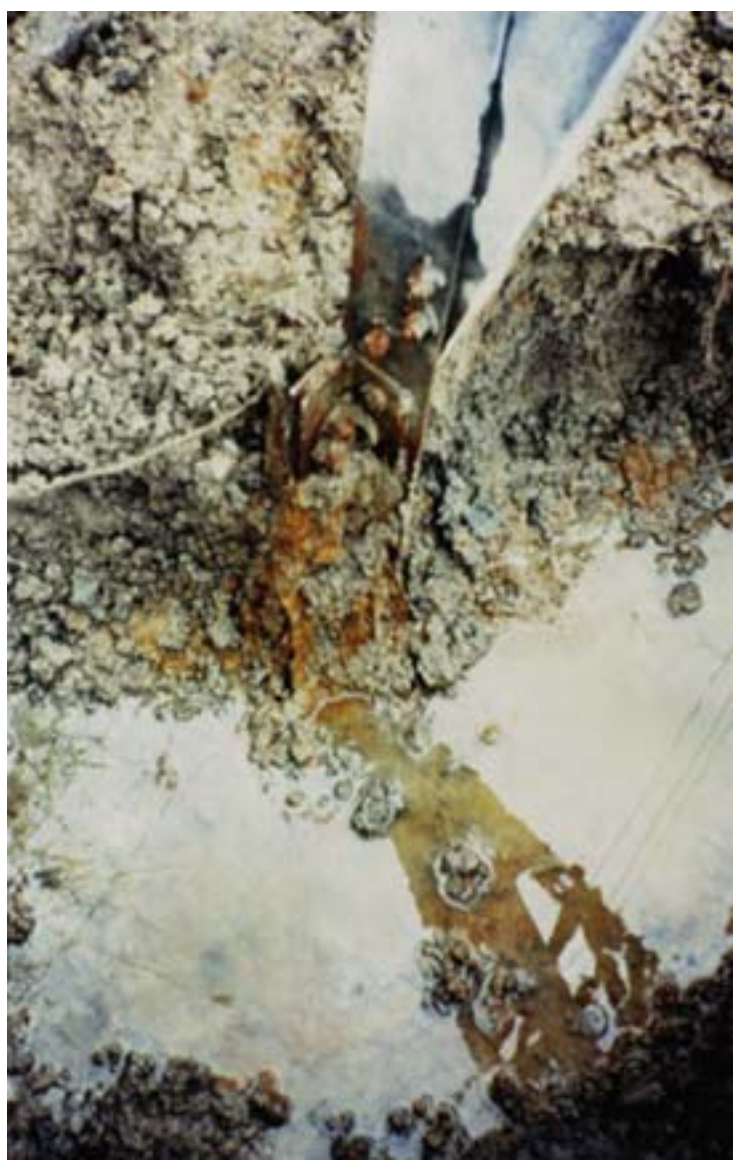

Figura 3. Corrosão na Base da Torre Metálica [3]. 
Logo, são utilizadas ligas de aço especiais para montagem da estrutura das torres. Entre esses metais, a Tabela I, a seguir, apresenta a composição de alguns desses materiais resistentes à corrosão atmosférica, cuja característica é relevante para identificação de eventuais riscos de corrosão:

TABELA I

LIGAS DE AÇO UTILIZADAS EM TORRES [3]

\begin{tabular}{|c|c|c|c|c|c|}
\hline & $\begin{array}{l}\text { COR- } \\
\text { TEN A }\end{array}$ & $\begin{array}{l}\text { COR- } \\
\text { TEN B }\end{array}$ & $\begin{array}{l}\text { COR- } \\
\text { TEN C }\end{array}$ & $\begin{array}{c}\text { NTU- } \\
\text { SAC- } \\
50-1\end{array}$ & $\begin{array}{c}\text { Aço } \\
\text { Carbobo }\end{array}$ \\
\hline $\mathrm{C}$ & $\begin{array}{c}0,12 \\
\text { (máx) }\end{array}$ & $\begin{array}{c}0,10- \\
0,19\end{array}$ & $\begin{array}{c}0,12- \\
0,19\end{array}$ & $\begin{array}{c}0,12 \\
\text { (máx) }\end{array}$ & 0,16 \\
\hline $\mathrm{Mn}$ & $0,20-0,50$ & $\begin{array}{c}0,90- \\
1,25\end{array}$ & $\begin{array}{c}0,90- \\
1,35\end{array}$ & 0,90 & 0,63 \\
\hline P & $0,07-0,15$ & $\begin{array}{l}0,040 \\
\text { (máx) }\end{array}$ & $\begin{array}{l}0,040 \\
\text { (máx) }\end{array}$ & $\begin{array}{c}0,06- \\
0,12\end{array}$ & 0,012 \\
\hline $\begin{array}{c}\mathrm{S} \\
\text { (máx) }\end{array}$ & 0,050 & 0,050 & 0,050 & 0,035 & 0,031 \\
\hline $\mathrm{Si}$ & $0,25-0,75$ & $\begin{array}{c}0,15- \\
0,30\end{array}$ & $\begin{array}{c}0,15- \\
0,30\end{array}$ & $\begin{array}{c}0,15- \\
0,35\end{array}$ & 0,012 \\
\hline $\mathrm{Cu}$ & $0,25-0,55$ & $\begin{array}{c}0,25- \\
0,40\end{array}$ & $\begin{array}{c}0,25- \\
0,40\end{array}$ & $\begin{array}{c}0,25- \\
0,50\end{array}$ & 0,01 \\
\hline $\mathrm{Cr}$ & $0,30-1,25$ & $\begin{array}{c}0,40- \\
0,65\end{array}$ & $\begin{array}{c}0,40- \\
0,70\end{array}$ & - & 0,03 \\
\hline $\mathrm{Ni}$ & $\begin{array}{c}0,65 \\
\text { (máx) }\end{array}$ & s. & . & - & 0,01 \\
\hline V & - & $\begin{array}{c}0,0,2- \\
0,10\end{array}$ & $\begin{array}{c}0,04- \\
0,10\end{array}$ & - & - \\
\hline $\mathrm{Ti}$ & - & - & - & $\begin{array}{l}0,15 \\
\text { (máx) }\end{array}$ & - \\
\hline
\end{tabular}

\section{PREVENÇÃo DA CORROSÃO EM TORRES DE TELECOMUNICAÇÕES}

A prevenção da corrosão em torres de telecomunicações pode ser feita a partir de diferentes intervenções, mas a que tem se mostrado mais eficaz é a galvanização de todas as peças de sua estrutura metálica [3]. Trata-se de um procedimento antigo, criado em 1741, pelo o químico francês $\mathrm{P}$. J. Melouin. Este pesquisador descobriu que uma camada de zinco sobre o aço poderia protegê-lo contra a corrosão. Em 1837, o engenheiro Sorel patenteou este processo com nome de galvanização a fogo.

O termo galvanização é atribuído à interação entre o aço e o zinco, uma vez em contato com um meio úmido, é criada uma diferença de potencial elétrico entre os metais e ocorre o fluxo de elétrons. Essa corrente recebe o nome de corrente galvânica, em homenagem ao pesquisador italiano Luigi Galvani (1737-1798), um dos primeiros interessados na eletricidade. A corrente galvânica protege o aço de outros processos químicos, entre esses, os processos corrosivos. O metal protegido funciona como catodo e não tem a sua massa oxidada no processo de oxi-redução. Essa proteção recebe o nome de proteção catódica com anodos de sacrifício ou galvânicos [4]. Para as torres, o zinco é o anodo de sacrifício, ou seja, o elemento que será corroído na superfície da torre, em sua camada de revestimento, protegendo a estrutura.

Logo, o principal objetivo da galvanização é impedir o contato do material base, o aço (uma liga de Ferro e Carbono), com o meio corrosivo. Isso é obtido com a imersão da peça da torre em um banho de zinco e alumínio fundido. O alumínio é o único que não exerce uma ação marcante, pois aparece com a quantidade abaixo de $0,006 \%$, e serve para abrilhantar a superfície de liga. Quantidades acima reduzem ou suprimem a reação entre o ferro e o zinco. Estes fatores são determinantes na formação da camada de zinco, e devem ser bem controlados, pois se verifica que o tempo de vida do revestimento depende da massa ou peso da cama de zinco [3].

A galvanização ou zincagem por imersão a quente tem seu processo definido para qualquer produto, podendo variar apenas na espessura da camada de revestimento, e ainda, dependendo da geometria da peça e da composição química do material base.

O estado da superfície deve ser avaliado, de modo que quanto mais rugosa for a superfície, mais espessa é a camada de zinco. Isso se deve pelo fato de se ter maior superfície exposta à reação entre o $\mathrm{Zn}$ e o Fe, e trazendo maior ancoragem mecânica da última camada, que fica por arraste durante a remoção da peça.

A velocidade de imersão e remoção da peça é assim avaliada: a imersão deve ser a mais rápida possível a fim de que a camada tenha o mesmo tempo de formação em toda a peça. O tempo recomendado varia entre 6 e $7 \mathrm{~min}$. Por sua vez, a remoção deve ser mais lenta e constante para proporcionar um revestimento mais uniforme. A última camada é formada 
por arraste de material da superfície do banho durante a remoção. Neste caso, o tempo recomendado é por volta de $1,5 \mathrm{~min}$ [3].

A temperatura do banho é avaliada a partir da temperatura de fusão do zinco, que está por volta de $419^{\circ} \mathrm{C}$, sugerindo uma temperatura de trabalho entre 430 e $460^{\circ} \mathrm{C}$. Se a temperatura for muito elevada poderá acelerar a reação entre o Ferro e o Zinco, gerando cristalizações grosseiras e frágeis, com uma aparência externa irregular, além de afetar seriamente a vida útil da cuba. Essas informações [5] podem ser observadas nas Tabelas II e III a seguir:

TABELA II

TEMPO DE IMERSÃO DA PEÇA POR ESPESSURA DESEJADA

\begin{tabular}{c|c|c}
\hline \multirow{2}{*}{$\begin{array}{c}\text { TEMPO DE } \\
\text { IMERSÃO }\end{array}$} & \multicolumn{2}{|c}{ Espessura $(\mu \mathrm{m})$} \\
\cline { 2 - 3 } & Sem jateamento & Com jateamento \\
\hline $15 \mathrm{~s}$ & 33 & 80 \\
$30 \mathrm{~s}$ & 52 & 110 \\
$60 \mathrm{~s}$ & 60 & 130 \\
2 min. & 82 & 180 \\
3 min. & 110 & 220 \\
4 min. & 130 & 240 \\
\hline
\end{tabular}

TABELA III

TABELA DE MASSA POR ESPESSURA DESEJADA

\begin{tabular}{|c|c|c|c|c|}
\hline \multirow{2}{*}{ MATERIAL } & \multicolumn{2}{|c|}{$\begin{array}{c}\text { Massa mínima por } \\
\text { unidade } \\
\text { de área }\left(\mathrm{g} / \mathrm{m}^{2}\right)\end{array}$} & \multicolumn{2}{|c|}{$\begin{array}{c}\text { Espessura mínima } \\
\text { equivalente } \\
\text { do revestimento }(\mu \mathrm{m})\end{array}$} \\
\hline & $\begin{array}{l}\text { Amostra } \\
\text { individual }\end{array}$ & $\begin{array}{l}\text { Média das } \\
\text { amostras }\end{array}$ & $\begin{array}{l}\text { Amostra } \\
\text { individual }\end{array}$ & $\begin{array}{l}\text { Média das } \\
\text { amostras }\end{array}$ \\
\hline $\begin{array}{l}\text { Fundidos } \\
\text { Conformados } \\
\text { mecanicament } \\
\text { e }\end{array}$ & 660 & 600 & 77 & 85 \\
\hline $\mathrm{e}<1,0 \mathrm{~mm}$ & 300 & 350 & 42 & 49 \\
\hline $\begin{array}{l}1,0 \mathrm{~mm} \leq \mathrm{e}< \\
3,0 \mathrm{~mm}\end{array}$ & 350 & 400 & 49 & 56 \\
\hline $\begin{array}{l}3,0 \mathrm{~mm} \leq \mathrm{e}< \\
6,0 \mathrm{~mm}\end{array}$ & 450 & 500 & 63 & 70 \\
\hline$e \geq 6,0$ & 530 & 600 & 74 & 84 \\
\hline
\end{tabular}

Após o banho são realizados o resfriamento e passivação da camada de zinco. Desta maneira, o revestimento de zinco estabiliza sua capa protetora. A passivação é feita com soluções cromatizantes a base de ácido crômico e bicromato, promovendo no produto zincado um aspecto amarelado. Para o acabamento é feita metalização (deposição de zinco por aspersão térmica) ou tinta com alto teor de zinco (maior que 90\%) [6].

Além disso, a montagem das peças da estrutura deve ser cuidadosamente observada, conforme disposição na Figura 4 a seguir:
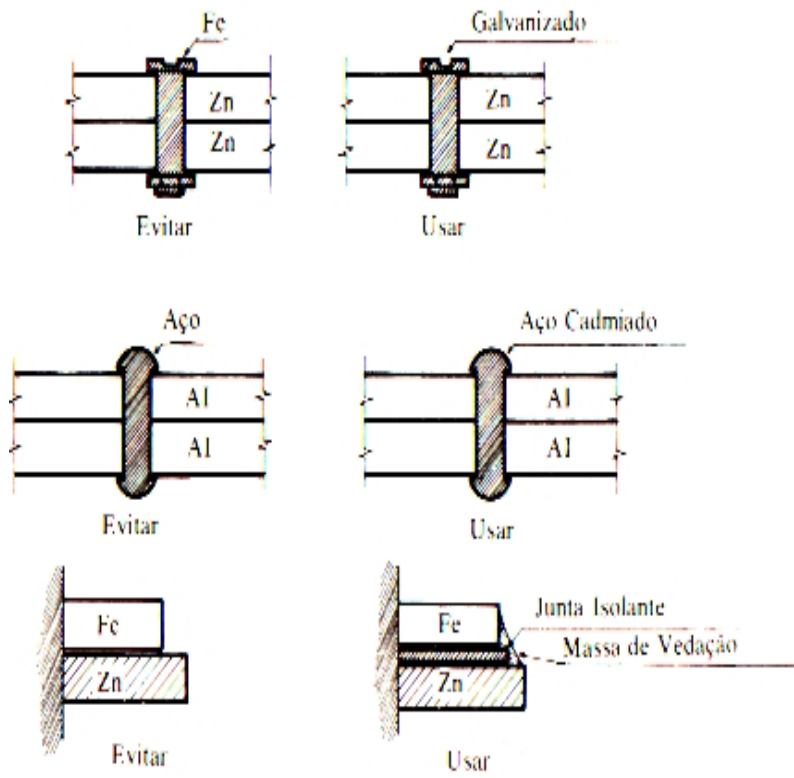

Figura 4. Cuidados para Montagem das Peças em Torres Telecomunicações [3].

\section{PREVENÇÃO DA CORROSÃO EM NORMAS DE TELECOMUNICAÇÕES}

A prevenção da corrosão em torres de telecomunicações está disposta em diferentes normas técnicas do setor. Essas normas, em geral, estabelecem os procedimentos de testes e inspeções para zincagem por imersão a quente das peças estruturais, chapas e acessórios compõem as estruturas das torres. Esses procedimentos têm por objetivo verificar o peso e a espessura da camada de zinco utilizada na galvanização das peças da estrutura da torre metálica. A Tabela IV apresenta os valores recomendados para o peso e espessura da camada de Zinco [7]: 
TABELA IV

ESPECIFICAÇÃO DA CAMADA DE ZINCO

\begin{tabular}{l|c|c}
\hline Classe do material & $\begin{array}{c}\text { Peso da camada } \\
\left(\mathrm{g} / \mathrm{m}^{2}\right)\end{array}$ & $\begin{array}{c}\text { Espessura } \\
(\mu \mathrm{m})\end{array}$ \\
\hline $\begin{array}{l}\text { Perfis e chapas } \\
\text { estruturais }\end{array}$ & 610 & 86 \\
\hline $\begin{array}{l}\text { Parafusos, porcas e } \\
\text { arruelas }\end{array}$ & 380 & 53 \\
\hline
\end{tabular}

O peso da camada de zinco deve ser calculado conforme descrição na fórmula (3) a seguir:

$$
\mathrm{P}=\frac{\mathrm{P}_{1}-\mathrm{P}_{2}}{\mathrm{~S}}
$$

Onde:

$\mathrm{P}$ : Peso da camada de zinco, em $\mathrm{g} / \mathrm{m}^{2}$.

$\mathrm{P}_{1}$ : Peso do corpo de prova zincado por imersão a quente, em g.

$\mathrm{P}_{2}$ : Peso do corpo de prova sem revestimento, em g.

$\mathrm{S}$ : Superfície do corpo de prova sem revestimento, em $\mathrm{m}^{2}$.

A espessura da camada de zinco pode ser obtida a partir da fórmula (4) a seguir:

$$
E=P \times f
$$

Onde:

E : Espessura em milimicrons $(\mu \mathrm{m})$.

$\mathrm{P}$ : Peso da camada de zinco, em $\mathrm{g} / \mathrm{m}^{2}$.

$\mathrm{f}$ : Fator de conversão $=0,14$.

A solução deve ficar em repouso por 48 horas, e seu volume em quantidade suficiente para cobrir a peça que terá a galvanização avaliada. Para imersão na solução, a peça deve ser preparada com uma pré-limpeza. Isso é feito utilizando-se uma mistura de $70 \%$ de tricloroetileno e $30 \%$ de xileno, para depois ser lavada em água corrente. Todas as impurezas devem ser removidas para avaliação da camada de zinco. Em seguida, a peça deve ser climatizada entre 15 e $21^{\circ} \mathrm{C}$ antes do início do ensaio [6]. A Tabela V apresenta um exemplo da relação linear entre a densidade e o volume do sulfato de cobre utilizado no ensaio:
TABela V

Densidade de Sulfato de

COBRE PARA O ENSAIO

\begin{tabular}{c|c}
\hline DENSIDADE & VOLUME $(\mathrm{mL})$ \\
\hline 1,186 & 0 \\
1,187 & 6 \\
1,188 & 11 \\
1,189 & 16 \\
1,190 & 21 \\
1,191 & 26 \\
1,192 & 31 \\
10 & 36 \\
1,194 & 41 \\
1,195 & 47 \\
1,196 & 52 \\
\hline
\end{tabular}

Assim, a peça é imersa na solução, verticalmente, sem agitação, durante 1 minuto. Para os perfis estruturais são exigidas 6 imersões, e 3 imersões para porcas e parafusos [6]. São exigidas ainda medidas locais de uniformidade do revestimento de camada de zinco sobre a peça, de acordo com a Norma ABNT 7399. Após a realização das imersões, se houver depósito brilhante e aderente de cobre na peça, de cor "vermelho salmão", existe a indicação de metal descoberto. Essa indicação apresenta a falha do processo de galvanização e, conseqüentemente, a vulnerabilidade da peça da torre para os processos corrosivos.

\section{CONSIDERACÕES FINAIS}

Destarte, os processos corrosivos apresentam-se como importantes inimigos das estruturas metálicas utilizadas em torres de telecomunicações. Por isso, as reações redoxes devem ser consideradas durante $\mathrm{o}$ projeto e instalação de uma torre com aplicação em telecomunicações.

Essas reações podem ser evitadas, ou simplesmente atenuadas, com a aplicação de processos de coíbam o efeito corrosivo. Um dos processos que podem atenuar a corrosão em torres é a galvanização das peças metálicas que compõe sua infra-estrutura. Esse processo protege a superfície do metal, mas pode apresentar falhas. Logo, existem 
inúmeras normas do setor que exigem procedimentos técnicos mínimos para garantir a qualidade da galvanização.

A galvanização das peças metálicas que integram a estrutura de uma torre deve ser considerada uma variável determinante na elaboração de um projeto técnico. Portanto, a abordagem desse processo na formação profissional apresenta-se de modo estratégico.

Para tanto, os ensaios que possibilitam a avaliação da galvanização devem ser utilizados como instrumentos de ensino e aprendizagem de engenheiros e técnicos. Tais ensaios, realizados em ambientes controlados, podem propiciar aos discentes ferramentas relevantes para inspeção da qualidade da camada protetora de zinco sobre peças e perfis metálicos, sua uniformidade, bem como a qualidade do produto final fabricado, isto é, a torre de telecomunicações. Além disso, em sala de aula, o docente pode estimular a produção do conhecimento a partir da discussão das recomendações técnicas da ABNT, entre outras, que definem os parâmetros mínimos de qualidade para realização desses processos de prevenção a corrosão nas torres metálicas.

Observa-se também que no âmbito das engenharias existe uma preocupação, de maneira significativa, com a prevenção da corrosão em estruturas metálicas. Estudos recentes apresentam algumas inovações para proteção adicional de peças e perfis metálicos, entre esses, destacam-se os novos processos que utilizam a energia induzida pelo campo elétrico de linhas de transmissão como proteção catódica anti-corrosão nas áreas de contato da estrutura e a sua respectiva fundação no solo, além da exposição à atmosfera em meios corrosivos. Trata-se de um campo de pesquisa recente, que pode ser explorado em trabalhos futuros, contribuindo de maneira relevante para redução de custos com o projeto, montagem e manutenção das estruturas metálicas que compõe as torres de telecomunicações.
Neste sentido, este trabalho procurou abordar os procedimentos básicos necessários para garantir a prevenção dos processos corrosivos em estruturas metálicas utilizadas em torres de telecomunicações. Para tanto, ficou evidente ainda a importância de se estudar as reações de oxidação e redução nos metais, bem com seus reflexos na sociedade moderna.

\section{REFERÊNCIAS}

[1] BARRADAS, Ovídio César Machado; SILVA, Gilberto Viana Ferreira. Telecomunicações - Sistemas de Radiovisibilidade. Rio de Janeiro: Embratel, 1978.

[2] TELEBRAS. Procedimentos para torres metálicas auto-suportadas, estaiadas e postes metálicos. Brasília: TELEBRAS Engenharia, n. ${ }^{\circ}$ 240.410.600, de 22 de outubro de 1997, 46p.

[3] GENTIL, Vicente. Corrosão, 2ed. Rio de Janeiro: Editora Guanabara, 1987, p. 1, 6, 8$20,9,11,66,92-110,101,314$, , 309-318, 385-419.

[4] HOFFMANN, João Nelson. Proteção Contra Corrosões nas Fundações das Torres Metálicas Utilizando Energia Induzida pelo Campo Elétrico da Linha de Transmissão. In: Espaço e Energia, ed.2. Curitiba: COPEL, 2005.

[5] TELEBRAS. Especificação Geral para Torres Estaiadas para suporte de antenas de microondas. Brasília: TELEBRAS Engenharia, n. ${ }^{\circ}$ 240.420.701, de 01 de maio de 1977, 31p.

[6] TELEBRAS. Procedimentos de testes e inspeções para zincagem por imersão a quente de peças estruturais, chapas e acessórios para torres. Brasília: TELEBRAS Engenharia, n. ${ }^{\circ}$ 240.301.500, de 02 de dezembro de 1983, 13p.

[7] REVISTA CONSTRUÇÃO METÁLICA $O$ que é galvanização a fogo: zincagem por imersão a quente. n. ${ }^{\circ}$ 50. São Paulo, Associação Brasileira da Construção Metálica, 2005. 